\title{
Avaliação da comercialização dos seguros florestais no Brasil
}

\author{
Rafaella Silva PEREIRA ${ }^{1}$, Sidney Araujo CORDEIRO ${ }^{1 *}$, Marcio Leles Romarco de OLIVEIRA ${ }^{1}$, \\ José Benedito GUIMARÃES JUNIOR ${ }^{2}$, Cristiano Christófaro MATOSINHOS ${ }^{1}$
}

\author{
${ }^{1}$ Departamento de Engenharia Florestal, Universidade Federal do Vale do Jequitinhonha e Mucuri, Diamantina, MG, Brasil. \\ ${ }^{2}$ Departamento de Engenharia dos Materiais, Universidade Federal de Lavras, Lavras, MG, Brasil. \\ *E-mail: sidney.cordeiro@ufvjm.edu.br
}

Recebido em julho/2017; Aceito em dezembro/2017.

\begin{abstract}
RESUMO: Este estudo realizou uma avaliação da comercialização dos seguros de florestais do Brasil, a fim de quantificar o seu comércio, bem como precificar o seu valor para plantios florestais do país. Os dados utilizados foram do Programa de Subvenção do Seguro Rural, no período de 2006 a 2015 e a simulação da cotação dos seguros de florestas foi feita por meio de um questionário de cotação automática de uma seguradora. Foram simuladas cotações para todas as espécies e todos os tipos de coberturas disponíveis no questionário, sendo elas: Eucalyptus spp., Pinus spp., Araucaria angustifolia, Hevea brasiliensis, Tectona grandis, Toona ciliat, Khaya ivorensis, Schizolobium amazonicum e Acacia spp., com cobertura básica (incêndio e raio) e coberturas adicionais (fenômenos meteorológicos: chuva excessiva, granizo, geada, seca e tromba d'água), ventos fortes e queda de aeronave. Apesar da área coberta por seguro de florestas integradas ao PSR representar um porcentual baixo das florestas totais plantadas no país, o mercado deve ser considerado promissor, pois percebe-se um aumento significativo da contratação deste seguro desde o ano de implementação do PSR. Os fatores que mais influenciam o valor do prêmio do seguro são: a espécie a ser segurada, o seu ciclo, idade, a finalidade de uso da madeira e o tipo de cobertura desejada na contratação da apólice do seguro.
\end{abstract}

Palavras-chave: Programa de Subvenção do Seguro Rural, mercado florestal, seguro rural.

\section{Evaluation of the commercialization of the forest insurance in Brazil}

\begin{abstract}
This study aims to make a diagnosis of the commercialization of the forest insurance of the Rural Insurance Subsidy Program of Brazil, in order to quantify its trade, as well as to price its value for the country's forest plantations. The data used are of a historical series between the years of 2006 to 2015 and the simulation of the forest insurance quotation was made through an automatic insurer quotation questionnaire. Quotations were simulated for all species and all types of hedges available in the questionnaire, including: Eucalyptus spp., Pinus spp., Araucaria angustifolia, Hevea brasiliensis, Tectona grandis, Toona ciliat, Khaya ivorensis, Schizolobium amazonicum e Acacia spp., with basic cover (fire and lightning) and additional coverages (meteorological phenomena: heavy rain, hail, frost, drought and water), strong winds and falling aircraft. To price the insurance, quotes were made with an insurer. Although the area covered by forest insurance integrated with the PSR represents a low percentage of the total planted forests in the country, the market should be considered promising, since there is a significant increase in the contracting of this insurance since the year of implementation of the PSR. The factors that most influence the value of the insurance premium are: the species to be insured, its cycle, age, the purpose of use of the wood and the type of desired coverage in the contracting of the insurance policy.
\end{abstract}

Keywords: Rural Insurance Subsidy Program, forestry market, rural insurance.

\section{INTRODUÇÃO}

O setor florestal é bastante susceptível às condições ambientais da região onde a atividade se insere. Sendo assim, os acontecimentos naturais envolvendo eventos meteorológicos podem comprometer grandemente a colheita das florestas. As intempéries e a manifestação de patógenos ou pragas são fenômenos que podem influenciar negativamente a produção florestal, causando perdas não esperadas na etapa do planejamento (REZENDE e OLIVEIRA, 2013). Esse conjunto de adversidades, colocam o setor em uma situação diferenciada quanto aos riscos enfrentados pelos produtores. E além desses, têm-se ainda, os riscos comuns a todas as atividades produtivas, como os tecnológicos, que se relacionam à evolução e ao conhecimento da tecnologia, além daqueles causados por oscilações na economia.

Diante disso, algumas medidas podem ser adotadas a fim de minimizar os prejuízos financeiros, caso algum tipo de desastre natural ocorra. Nota-se então, a prática de determinadas alternativas, como os seguros. O Ministério da Agricultura, Pecuária e Abastecimento (MAPA), tem procurado criar condições para o desenvolvimento do seguro rural. A primeira iniciativa governamental de impacto foi a criação do Programa de Subvenção do Seguro Rural (PSR). Dentre os seguros rurais interligados ao PSR, tem-se o seguro de florestas, cujo objetivo é a garantia do pagamento de indenização pelos prejuízos causados nas florestas seguradas, identificadas e caracterizadas na apólice, desde que tenham 
decorrido diretamente de um ou mais riscos cobertos (SUSEP, 2016).

Além da susceptibilidade aos fenômenos naturais, o investimento no setor florestal é alto e, na maioria das vezes, o retorno financeiro se dá a longo prazo. Assim, o seguro de florestas se torna uma excelente alternativa para a mitigação de riscos. Mas, por ser um tipo de apólice bem específico, a sua comercialização é pequena, muitos produtores rurais ainda o desconhecem e quando conhecem, possuem dúvidas a respeito.

O mercado do seguro de florestas no Brasil é uma realidade que precisa ser melhor estudada e aprimorada. Diante disso,O presente estudo tem como objetivo realizou uma avaliação histórica da comercialização do seguro de florestas do PSR, a fim de quantificar o comércio do seguro de florestas, bem como precificar o valor deste seguro para os principais tipos de plantios florestais do Brasil.

\section{MATERIAL E MÉTODOS}

2.1 Fonte e coleta dos dados

Para realizar este trabalho foram empregados isoladamente, e de forma combinada, diversas técnicas de busca de informações e análises, com enfoque metodológico denominado pesquisa rápida. Esse método é utilizado quando se tem algumas limitações de execução no estudo, principalmente ligados ao período e aos recursos disponíveis para executá-lo. Em geral, métodos mais precisos de coleta de informações são mais caros e demorados (IEL/CNA/SEBRAE, 2000). Aqui, o método empírico baseou-se na utilização desse enfoque metodológico de busca de informações, associado ao uso intensivo de informações de fontes secundárias. Os dados e as informações necessárias para a realização deste estudo foram obtidos em diferentes fontes, como: livros, revistas, teses e material disponível online na internet em sites de renome na área econômica e florestal, além de sites governamentais.

Os dados utilizados para realizar a avaliação da comercialização do seguro de florestas no Brasil, representam uma série histórica entre os anos de 2006 a 2015, e são referentes aos seguros de florestas integrantes do Programa de Subvenção do Seguro Rural (PSR). Foram obtidos pelo sistema online denominado "Atlas do Seguro Rural" pertencente ao MAPA (2016a).

A simulação da cotação dos seguros de florestas foi feita por meio de um questionário de cotação automática de uma seguradora. Foram analisados também os questionários das outras seguradoras que oferecem o seguro de florestas, mas a escolha da seguradora em questão se deu pela maior facilidade de obtenção dos dados e por ser considerada a mais completa das analisadas. O questionário disponibilizado por essa seguradora é uma planilha eletrônica automática, que uma vez preenchida adequadamente, fornece a simulação automática dos valores do seguro pretendido.

Foram simuladas cotações para todas as espécies e todos os tipos de coberturas disponíveis no questionário, sendo elas: eucalipto (Eucalyptus spp.), pinus (Pinus elliotti em específico e outros Pinus spp.), araucária (Araucaria angustifolia), seringueira (Hevea brasiliensis), teca (Tectona grandis), cedro australiano (Toona ciliata), mogno africano (Khaya ivorensis), paricá (Schizolobium amazonicum) e acácia (Acacia spp.), com cobertura básica (incêndio e raio) e coberturas adicionais (fenômenos meteorológicos: chuva excessiva, granizo, geada, seca e tromba d'água), ventos fortes e queda de aeronave. Na simulação considerou-se uma área de 1 hectare, onde o tipo de manejo (relacionado com a finalidade de uso da madeira) adotado seguiu as opções disponíveis no questionário. Cada uma das espécies apresenta finalidades específicas no questionário: o eucalipto tem a finalidade de ser utilizado para celulose/energia ou serraria/laminação; o Pinus elliotti para resinagem ou serraria/laminação; o Pinus spp só para serraria/laminação; a araucária, teca e cedro australiano para serraria/laminação; a seringueira para produção de látex; o paricá para corte raso para posterior laminação; e a acácia para uso múltiplo. Calculou-se o valor do prêmio considerando o ano de 2016 como o último ano do ciclo de plantio de cada uma das espécies apresentadas. A definição da cidade onde o plantio está localizado foi feita com base em pesquisas na literatura. Buscou-se cidades onde tem-se estudos de cada uma das espécies escolhidas. $\mathrm{O}$ valor da subvenção considerado foi de $45 \%$ do valor do prêmio, já predefinido pelo questionário, e o valor pago pelo segurado é obtido por meio da subtração do valor do prêmio pela subvenção, caso ela ocorra.

\subsection{Processamento e análise dos dados}

Os dados da série histórica foram coletados durante dois meses de pesquisa (maio e junho de 2016) e tabulados em planilha eletrônica; reorganizados, apurados e pósprocessados em valores percentuais de forma a facilitar a análise. Esse procedimento de tabulação e processamento de informações se assemelha ao realizado por Silva et al. (2009).

Os dados da simulação da cotação dos valores do seguro de florestas também foram tabulados em planilha eletrônica e reorganizados, de forma que facilitasse o seu entendimento.

\section{RESULTADOS}

3.1. O Programa de Subvenção do Seguro Rural e seguro de florestas no Brasil

Foram encontradas onze seguradoras associadas ao PSR (Tabela 1), dentre elas, a Aliança do Brasil é a que possui maior número de apólices contratadas, área assegurada, valor assegurado, prêmio de seguro e subvenção. Em um segundo plano de destaque pode-se citar as seguradoras Mapfre, Swiss Re e Nobre. As culturas citadas acima estão incluídas na modalidade seguro agrícola do seguro rural.Ao observar a Tabela 2, nota-se que se tem apenas três seguradoras, interligadas ao PSR, que comercializam o seguro de florestas ao longo dos anos estudados, sendo elas: Allianz, Mapfre e Swiss Re. A Mapfre é a que, durante o período estudado, deteve um maior valor de prêmio de seguros e subvenção, enquanto que a Allianz teve um maior número de apólices contratadas e a Swiss Re teve uma maior área e valor assegurado.

3.2. Levantamento histórico e atual das florestas seguradas no Brasil

Analisando a Tabela 3, percebe-se que o seguro de florestas interligado ao PSR, corresponde a aproximadamente $2,64 \%$ da área assegurada no Brasil e a 5,81\% do valor assegurado por seguro rural no país ao longo do período analisado. O pagamento da subvenção ao prêmio do seguro de florestas foi da ordem de $\mathrm{R} \$ 11.277 .784,00$, desde o ano de 2006 até 2015; o que amparou a aquisição de 2.025 apólices contratadas, garantindo um valor segurado de $\mathrm{R} \$$ 4.966.889.712,76 e proporcionando cobertura securitária para uma área de 1.382.199,25 hectares de florestas desde o 
lançamento do programa. De maneira geral, houve um aumento gradativo em todos os aspectos analisados entre os anos 2006 e 2014, com uma queda brusca no ano de 2015 (Tabela 4).Nota-se que a área coberta por seguro de florestas (348.568 hectares) integradas ao PSR no ano de 2014, corresponde a aproximadamente $3,72 \%$ da área total de plantio no território brasileiro $(9.361 .153$ hectares $)$ nesse mesmo ano (Tabela 5).

A simulação da cotação dos seguros de florestas realizada está representada na Tabela 6 , onde os valores apresentados se referem a um hectare de área plantada pagos anualmente conforme a idade do plantio.

Tabela 1. Histórico de apólices contratadas, área segurada, valor segurado, prêmio de seguro e valor de subvenção de cada seguradora de seguro rural ligada ao PSR do Brasil, ao longo dos anos de 2006 a 2015.

Table 1. History of contracted policies, insured area, insured amount, insurance premium and subsidy value of each rural insurance insurer linked to the RSP of Brazil, over the years 2006 to 2015.

\begin{tabular}{lccccc}
\hline Seguradora & $\begin{array}{c}\text { Apólices } \\
\text { Contratadas }\end{array}$ & $\begin{array}{c}\text { Área Segurada } \\
(\text { ha) }\end{array}$ & $\begin{array}{c}\text { Valor Segurado (LMGA) } \\
(\mathrm{R} \$)\end{array}$ & $\begin{array}{c}\text { Prêmio do Seguro } \\
(\mathrm{R} \$)\end{array}$ & $\begin{array}{c}\text { Valor da Subvenção } \\
(\mathrm{R} \$)\end{array}$ \\
\hline Itaú & 9,00 & $25.106,68$ & $29.999 .997,00$ & $1.756 .790,01$ & $255.405,88$ \\
Mapfre & $98.599,00$ & $5.010 .977,61$ & $12.796 .877 .411,41$ & $553.159 .979,32$ & $297.109 .850,51$ \\
Aliança do Brasil & $299.780,00$ & $34.675 .394,44$ & $45.457 .985 .050,69$ & $2.644 .247 .823,21$ & $1.442 .102 .904,77$ \\
Excelsior & 134,00 & $6.598,47$ & $14.313 .556,81$ & $1.015 .632,42$ & $420.436,78$ \\
Fairfax & $1.462,00$ & $100.114,27$ & $187.855 .126,66$ & $12.749 .774,35$ & $6.810 .274,28$ \\
Nobre & $80.208,00$ & $2.685 .945,12$ & $8.112 .633 .250,74$ & $612.658 .293,98$ & $349.151 .555,56$ \\
Swiss Re & $52.949,00$ & $4.789 .401,69$ & $9.699 .557 .711,57$ & $482.634 .634,46$ & $257.918 .616,62$ \\
Essor & $33.736,00$ & $1.655 .284,52$ & $3.899 .587 .533,62$ & $343.375 .206,09$ & $199.632 .668,36$ \\
Allianz & $30.893,00$ & $2.866 .536,38$ & $3.276 .623 .619,27$ & $203.974 .078,57$ & $115.231 .747,74$ \\
Sancor & $4.473,00$ & $367.724,62$ & $459.234 .731,57$ & $49.386 .613,49$ & $31.042 .056,00$ \\
Porto Seguro & $15.555,00$ & $78.794,91$ & $1.531 .374 .727,38$ & $177.248 .660,14$ & $95.452 .056,12$ \\
\hline Total & $617.798,00$ & $52.261 .878,71$ & $85.466 .042 .716,72$ & $5.082 .207 .486,04$ & $2.795 .127 .572,62$ \\
\hline
\end{tabular}

Tabela 2. Relação de apólices contratadas, área segurada, valor segurado, prêmio do seguro e valor da subvenção de seguros de florestas, por cada seguradora ligada ao PSR do Brasil, entre os anos de 2006 a 2015.

Table 2. List of contracted policies, insured area, insured value, insurance premium and value of the forest insurance subsidy, for each insurer linked to the Brazilian PSR between the years of 2006 to 2015.

\begin{tabular}{lccccc}
\hline Seguradora & $\begin{array}{c}\text { Apólices } \\
\text { Contratadas }\end{array}$ & $\begin{array}{c}\text { Área Segurada } \\
\text { (ha) }\end{array}$ & $\begin{array}{c}\text { Valor Segurado (LMGA) } \\
(\mathrm{R} \$)\end{array}$ & $\begin{array}{c}\text { Prêmio do Seguro } \\
(\mathrm{R} \$)\end{array}$ & $\begin{array}{c}\text { Valor da Subvenção } \\
(\mathrm{R} \$)\end{array}$ \\
\hline Allianz & $1.008,00$ & $283.221,79$ & $872.147 .515,13$ & $12.055 .778,81$ & $4.005 .859,72$ \\
Mapfre & 975,00 & $343.443,10$ & $1.982 .625 .359,28$ & $18.332 .476,37$ & $6.524 .019,10$ \\
Swiss Re & 42,00 & $755.534,36$ & $2.112 .116 .838,35$ & $13.049 .311,79$ & $747.905,23$ \\
\hline Total & $2.025,00$ & $1.382 .199,25$ & $4.966 .889 .712,76$ & $43.437 .566,97$ & $11.277 .784,05$ \\
\hline
\end{tabular}

Tabela 3. Porcentagem relativa de apólices contratadas, área segurada, valor segurado, prêmio de seguro e valor de subvenção do seguro de florestas dentro do seguro rural ligados ao PSR do Brasil, ao longo dos anos de 2006 a 2015.

Table 3. Relative percentage of contracted policies, insured area, insured amount, insurance premium and subsidy value of the rural insurance insurance linked to the RSP of Brazil, over the years 2006 to 2015.

\begin{tabular}{lccccc}
\hline & Apólices & Área Segurada & Valor Segurado (LMGA) & Prêmio do Seguro & Valor da Subvenção \\
& Contratadas & $($ ha) & $(\mathrm{R} \$)$ & $(\mathrm{R} \$)$ & $2.795)$ \\
\hline Seguro Rural & $617.798,00$ & $52.261 .878,71$ & $85.466 .042 .716,72$ & $5.082 .207 .486,04$ & $2.795 .127 .572,62$ \\
Seguro de Florestas & $2.025,00$ & $1.382 .199,25$ & $4.966 .889 .712,76$ & $43.437 .566,97$ & $11.277 .784,05$ \\
$\%$ & 0,33 & 2,64 & 5,81 & 0,85 & 0,40 \\
\hline
\end{tabular}

Tabela 4. Histórico de apólices contratadas, área segurada, valor segurado, prêmio do seguro e valor da subvenção do seguro de florestas do Brasil ligados ao PSR, ao longo dos anos de 2006 a 2015.

Table 4. History of contracted policies, insured area, insured value, insurance premium and value of the Brazilian forest insurance subsidy linked to the PSR, over the years 2006 to 2015.

\begin{tabular}{cccccc}
\hline Ano & $\begin{array}{c}\text { Apólices } \\
\text { Contratadas }\end{array}$ & $\begin{array}{c}\text { Área Segurada } \\
(\text { ha) }\end{array}$ & $\begin{array}{c}\text { Valor Segurado (LMGA) } \\
(\mathrm{R} \$)\end{array}$ & $\begin{array}{c}\text { Prêmio do Seguro } \\
(\mathrm{R} \$)\end{array}$ & $\begin{array}{c}\text { Valor da Subvenção } \\
(\mathrm{R} \$)\end{array}$ \\
\hline 2006 & 7 & $79.903,32$ & $1.336 .610 .103,18$ & $1.742 .978,04$ & $39.391,35$ \\
2007 & 54 & $50.207,61$ & $70.610 .987,21$ & $958.691,68$ & $246.035,88$ \\
2008 & 121 & $44.589,92$ & $105.887 .358,99$ & $1.193 .217,74$ & $342.882,98$ \\
2009 & 244 & $67.652,37$ & $431.613 .615,32$ & $3.496 .688,16$ & $757.170,74$ \\
2010 & 241 & $150.156,54$ & $324.823 .805,63$ & $4.704 .198,69$ & $884.760,03$ \\
2011 & 245 & $183.792,00$ & $450.798 .917,51$ & $5.460 .077,16$ & $1.002 .233,04$ \\
2012 & 269 & $209.902,82$ & $507.623 .039,51$ & $6.582 .692,90$ & $1.246 .857,74$ \\
2013 & 344 & $204.181,79$ & $915.478 .516,86$ & $7.245 .748,72$ & $2.515 .535,65$ \\
2014 & 406 & $348.567,59$ & $706.475 .728,87$ & $10.216 .151,49$ & $3.424 .974,23$ \\
2015 & 94 & $43.245,29$ & $116.967 .639,68$ & $1.837 .122,39$ & $817.942,41$ \\
\hline Total & 2025 & $1.282 .199,25$ & $4.966 .889 .712,76$ & $43.437 .566,97$ & $11.277 .784,05$ \\
\hline
\end{tabular}


Tabela 5. Área segurada (em hectares) por seguro de florestas ligados ao PSR do Brasil e área de árvores plantadas (em hectares), por estado e Distrito Federal no ano de 2014 por estado, Brasil.

Table 5. Insured area (in hectares) by insurance of forests linked to the RSP of Brazil and tree planted areas (in hectares), by state and Federal District in the year 2014 by state, Brazil.

\begin{tabular}{lccccc}
\hline \multirow{2}{*}{ Estado } & \multicolumn{3}{c}{ Área plantada com árvores (ha) } & \multirow{2}{*}{ Área Segurada (ha) } \\
\cline { 2 - 5 } MG & Eucalipto & Pinus & Outras & Total & $23.117,03$ \\
MS & $1.713 .576,00$ & $47.557,00$ & $1.906,00$ & $1.763 .039,00$ & $42.630,69$ \\
SP & $886.381,00$ & $5.700,00$ & - & $892.081,00$ & $26.897,81$ \\
PR & $870.776,00$ & $129.711,00$ & $1.293,00$ & $1.001 .780,00$ & $24.445,91$ \\
RS & $687.635,00$ & $909.874,00$ & $24.652,00$ & $1.622 .161,00$ & $167.142,37$ \\
BA & $678.956,00$ & $288.910,00$ & $135.059,00$ & $1.102 .925,00$ & $3.018,00$ \\
SC & $540.648,00$ & - & 30,00 & $540.678,00$ & 673,64 \\
ES & $368.485,00$ & $654.822,00$ & $10.317,00$ & $1.033 .624,00$ & 62,80 \\
MT & $247.871,00$ & $1.690,00$ & 60,00 & $249.621,00$ & $12.637,60$ \\
MA & $212.815,00$ & - & $70.723,00$ & $283.538,00$ & $1.445,50$ \\
PA & $207.448,00$ & - & 11,00 & $207.459,00$ & - \\
TO & $164.139,00$ & - & $42.833,00$ & $206.972,00$ & $45.925,13$ \\
GO & $134.352,00$ & 740,00 & $8.503,00$ & $143.595,00$ & 483,00 \\
PI & $117.051,00$ & $8.880,00$ & $1.122,00$ & $127.053,00$ & - \\
RJ & $37.630,00$ & - & - & $37.630,00$ & 88,11 \\
AP & $36.870,00$ & 16,00 & 848,00 & $37.734,00$ & - \\
AL & $34.885,00$ & 384,00 & $1.328,00$ & $36.597,00$ & - \\
SE & $5.213,00$ & - & 311,00 & $5.524,00$ & - \\
PB & $3.129,00$ & - & 30,00 & $3.159,00$ & - \\
CE & 418,00 & - & $5.048,00$ & $5.466,00$ & - \\
RO & 42,00 & - & - & 42,00 & - \\
RR & 16,00 & - & $13.367,00$ & $13.383,00$ & - \\
\hline Total & $-948.336,00$ & $2.048 .284,00$ & $364.533,00$ & $9.361 .153,00$ & $47.941,74$ \\
\hline
\end{tabular}

\section{DISCUSSÃO}

Por meio do PSR, o governo federal brasileiro apoia financeiramente àqueles produtores que contratarem o seguro rural, através de auxílio financeiro para o pagamento do prêmio do seguro rural, reduzindo o custo para o produtor. $\mathrm{O}$ percentual de subvenção pago por tal varia de $40 \%$ a $60 \%$ de acordo com as prioridades da política agrícola formulada pelo MAPA. As modalidades de seguro rural amparadas pelo PSR são: agrícola, pecuária, florestas e aquícola (MAPA, 2016b).

Ao longo da série histórica dos dados estudados, as culturas do trigo, soja e milho; e os estados do Rio Grande do Sul e Paraná são os maiores destaques no mercado de seguro rural no Brasil.

Considerando apenas os dados trabalhados com referência ao ano de 2015, as seguradoras Allianz e Mapfre dividiram a liderança do mercado de seguro de florestas. A primeira fechou o ano com 52 apólices contratadas, para proteger 29.381,46 hectares, em um valor assegurado de R\$ 53.745.982,33, com prêmio R $\$ 862.998,35$ e subvenção de R\$ 321.191,69. Já a Mapfre, teve 42 apólices contratadas, cobrindo uma área de 13.863,83 hectares, em um valor assegurado de $\mathrm{R} \$ 63.221 .657,35$, com prêmio pago no valor de $\mathrm{R} \$ 974.124,04$ e subvenção do governo no valor R\$ 496.750,72.

\subsection{Levantamento histórico e atual das florestas seguradas no} Brasil

Aproximadamente $\quad 0,9 \%$ do território brasileiro corresponde a área ocupada por florestas plantadas (IBÁ, 2015) e apesar de contar com uma extensa área plantada, os dados analisados neste estudo traduzem uma taxa mínima de contratação dos seguros de florestas. Nos anos de 2006 a 2015, observa-se que a comercialização de contratos do seguro de florestas no Brasil apesar de ainda incipiente, tem crescido, e o valor destinado aos incentivos do governo, também vêm aumentando.

De maneira geral, houve um aumento gradativo em todos os aspectos analisados entre os anos 2006 e 2014, com uma queda brusca no ano de 2015 (Tabela 4), causada provavelmente pela crise econômico-financeira pela qual o Brasil tem passado ultimamente. $\mathrm{O}$ valor assegurado teve a sua mais alta importância no ano 2006, que foi lançamento do programa. Desde o ano de 2006 até 2014, tem-se um aumento de aproximadamente 58 vezes o número de apólices de seguro de florestas contratadas e a área assegurada do país mais que quadruplicou nesse período. Só no ano de 2015, apesar da crise econômico-financeira no país, aproximadamente $2,2 \%$ do valor assegurado por seguros rurais comercializados, são da modalidade seguros de florestas. Foram 94 apólices de seguros de florestas vendidas no Brasil em 2015, em um total de 43.545,29 hectares assegurados, importância segurada no valor de $\mathrm{R} \$ 116.967 .639,68$, prêmio de $\mathrm{R} \$ 1.837 .122,39$ e subvenção de $\mathrm{R} \$ 817.942,41$.

Como efeito colateral da crise econômico-financeira, que trouxe a economia brasileira para a situação de fragilidade em que se encontra recentemente, tem-se a perda de competitividade da indústria brasileira de árvores plantadas. O setor, além de questões estruturais, tem que conviver com desafios específicos da área, como: investimentos a longo prazo (na maioria das vezes), riscos de desastres naturais, susceptibilidade às condições ambientais da área do plantio, intempéries, manifestação de patógenos e pragas. Apesar do cenário econômico adverso, enfrentado desde o ano de 2014 até os dias atuais, tal setor encerrou 2014 com resultado positivo em seus principais indicadores de desempenho (IBÁ, 2015).

Os valores encontrados na Tabela 5 podem ser considerados bastante insignificantes diante da área total 
plantada no país, o que demonstra que o setor, praticamente desconhece o mercado do seguro de florestas ou tem receio em contratá-lo. Comparou-se a área coberta pelo seguro de florestas com a área total do plantio apenas para o ano de 2014 porque na ocasião de coleta dos dados, 2014 era o último ano com dados disponíveis de áreas de florestas plantadas no Brasil.

O estado de Minas Gerais, apesar de ser o que possuía maior área de florestas plantadas do país no ano de 2014, com um total de 1.763.039 hectares, teve apenas 23.117,03 hectares de florestas seguradas em 2014, o que corresponde a menos que $1,32 \%$ das florestas totais do estado. Em contrapartida, o estado do Rio Grande do Sul é o que teve maior área segurada (167.142,37 hectares), representando cerca de $15,15 \%$ da área total de plantio do estado; mas estava na quinta posição no ranking de florestas plantadas no país com 1.102.925 hectares nesse referido ano. O estado do Tocantins e Mato Grosso do Sul também tiveram uma posição que pode ser considerada de destaque no que se refere à contratação de seguros de florestas, com 45.925,13 e 42.630,69 hectares, respectivamente, de florestas seguradas em 2014. A área segurada do estado do Tocantins representa aproximadamente $32 \%$ da área total plantada no Estado.

Esse valor tão baixo de adesão ao seguro de florestas, pode estar relacionado ao fato de que essa modalidade de seguro rural ainda é muito recente no Brasil. O setor carece de informações e muitos produtores o desconhecem. Mas, por outro lado, esse cenário pode vir a chamar a atenção das empresas seguradoras, que poderão começar a apostar e investir mais nesse mercado, além oferecer novos tipos de cobertura.

Nos últimos anos, investidores financeiros ou TIMOs do inglês Timber Investment Management Organizations detém 10,2\% dos plantios de árvores no Brasil. Hoje, o país já é o segundo principal destino dos investimentos em ativos florestais, com $29 \%$ do montante total de investimentos na atividade, atrás somente dos Estados Unidos, que concentram $66 \%$ (IBÁ, 2015). Com esse aumento de investidores estrangeiros, comprando florestas no Brasil, possivelmente a importância do seguro tende a se disseminar e consequentemente, a sua comercialização também.

A adoção de campanhas de divulgação do seguro de florestas junto a órgãos como Instituto Estadual de Florestas (IEF), Sindicatos de Produtores Rurais e outros órgãos regionais, de maneira poderiam funcionar como um meio de exposição do seguro de florestas e os seus benefícios para o produtor rural. Isso poderia ser feito por meio de panfletos ou cartilhas ilustrativas e de leitura fácil. Assim, permitiria ao produtor um maior conhecimento de tal modalidade do seguro rural, podendo contratá-lo quando julgar conveniente. Tal alternativa pode cobrir a lacuna do desconhecimento ou falta de informações consistentes sobre essa modalidade de seguro rural por parte do produtor.

A indenização recebida por meio do seguro de florestas possibilita a realização de investimentos produtivos e a subvenção do PSR permite um menor gasto na contratação do seguro. O seguro pode ser considerado um meio de diminuir a inadimplência do produtor com as instituições financeiras que concedem crédito rural, pois garante recursos para liquidar a dívida contraída. Se o produtor mantém os seus recursos, ele pode garantir a geração de empregos em campo e a contratação de tecnologias cada vez mais eficientes, pois terá uma maior estabilidade econômica.

O prejuízo no setor florestal, principalmente aqueles causados por riscos ambientais cobertos por seguros de florestas, gera também perdas na sociedade como um todo. Essas perdas podem estar ligadas à diminuição da disponibilidade de produtos madeireiros no mercado, ou pela redução em outras atividades ligadas aos setores secundários e terciários da economia.

\subsection{Simulação de cotação do seguro de florestas para diferentes povoamentos florestais}

De acordo com os resultados da Tabela 6, percebe-se que os fatores que mais influenciam no valor do risco da área do seguro de florestas estão relacionados basicamente a três aspectos importantes: manejo, implementação e condução do plantio; localização do plantio; e estrutura da fazenda onde o plantio está inserido.

Aspectos relacionados ao manejo, implementação e condução da área do plantio, estão baseados principalmente nas seguintes características: espécie plantada proveniente de sementes ou clones; regime de condução do plantio de alto fuste ou condução de rebrota e se há existência de assistência técnica especializada para condução do plantio. Plantios de eucaliptos desenvolvidos pelo uso de mudas oriundas de sementes, por exemplo, podem apresentar variações provenientes da polinização cruzada entre as plantas matrizes, o que não ocorre com plantios originários de mudas clonais. Essa variação causa diferenças entre árvores para diversas características. Sendo assim, uma árvore pode apresentar maior ou menor resistência e/ou tolerância a doenças, diferentes taxas de crescimento, distintas propriedades da madeira, entre outros fatores, em relação as outras do mesmo plantio (FILHO et al., 2006). Da mesma forma, essas árvores podem exibir comportamento diferenciado frente aos fenômenos meteorológicos como geada ou seca, excesso de umidade e ventos fortes, o que influenciará no valor final do seguro.

Quanto à localização tem-se as seguintes particularidades que podem influenciar na diminuição ou aumento do valor do prêmio do seguro: propriedades próximas às vias asfaltadas, que detêm grandes fluxos de carros; presença de empresas florestais na região; plantios em áreas com histórico de ventos fortes, incidência de raios ou de inundação.

Com relação à estrutura da fazenda são observados: existência de formas de detecção e de aviso em caso de ocorrência de incêndios; presença de torres de controle de incêndios, vigilância, brigadas ou convênios com cooperativas de combate a incêndio; se há estação meteorológica, reservatórios, rios, poços d'água; aceiros definidos e frequência de limpeza dos mesmos; se a azenda conta com caminhões ou carretas e ferramentas de combate aos incêndios; e também a inclinação do terreno onde se localiza o plantio. Todos esses fatores influenciam na rapidez e eficiência na detecção e monitoramento dos incêndios florestais. Eles são considerados fundamentais para a viabilização do controle do fogo, redução dos custos nas operações de combate e atenuação dos danos. As torres têm um papel fundamental, pois servem para monitorar e auxiliar na identificação do local de ocorrência do incêndio e sabe-se que um conhecimento inadequado da localização do incêndio e extensão da área queimada prejudica a estimativa do impacto do fogo sobre o ambiente (BATISTA, 2004). 
Tabela 6 - Simulação da cotação dos seguros de florestas para as espécies (para um hectare): eucalipto, Pinus elliotti, Pinus spp., araucária, seringueira, teca, cedro australiano, mogno africano, paricá e acácia com cobertura básica (incêndio + raio) e coberturas adicionais (fenômenos meteorológicos, ventos fortes e queda de aeronave).

Table 6 - Simulation of forest insurance rates for species (for one hectare): eucalyptus, Pinus elliotti, Pinus spp., Araucaria, rubber tree, teak, Australian cedar, African mahogany, paricá and acacia with basic coverage (fire + radius) and additional coverages (meteorological phenomena, strong winds and aircraft fall).

\begin{tabular}{|c|c|c|c|c|c|c|c|c|c|}
\hline Espécie & Cidade/Estado & $\begin{array}{l}\text { Tipo de } \\
\text { manejo }\end{array}$ & Ciclo & $\begin{array}{l}\text { Valor em } \\
\text { Risco } \\
\text { (R\$/ha) }\end{array}$ & $\begin{array}{c}\text { Participação } \\
\text { Obrigatória do } \\
\text { Segurado } \\
\text { Mínimo (R\$) }\end{array}$ & Cobertura & $\begin{array}{l}\text { Prêmio } \\
\text { Líquido } \\
\text { (R\$) }\end{array}$ & $\begin{array}{c}\text { Valor da } \\
\text { Subvenção } \\
\text { (R\$) }\end{array}$ & $\begin{array}{l}\text { Valor pago } \\
\text { pelo } \\
\text { produtor } \\
(\mathrm{R} \$)\end{array}$ \\
\hline \multirow{4}{*}{ Eucalipto } & \multirow{4}{*}{$\begin{array}{c}\text { Diamantina/ } \\
\text { MG }\end{array}$} & \multirow{4}{*}{$\begin{array}{l}\text { Celulose/ } \\
\text { Energia }\end{array}$} & \multirow{4}{*}{$\begin{array}{c}7 \\
\text { anos }\end{array}$} & \multirow{4}{*}{$11.286,00$} & \multirow{4}{*}{564,3} & Básica Incêndio + Raio & 126,65 & 56,99 & 69,66 \\
\hline & & & & & & Fenômenos Meteorológicos & 85,27 & 38,37 & 46,9 \\
\hline & & & & & & Ventos Fortes & 37,62 & 16,93 & 20,69 \\
\hline & & & & & & Queda de Aeronave & 12,54 & 5,64 & 6,9 \\
\hline \multirow{4}{*}{ Eucalipto } & \multirow{4}{*}{$\begin{array}{c}\text { Diamantina/ } \\
\text { MG }\end{array}$} & \multirow{4}{*}{$\begin{array}{c}\text { Serraria/ } \\
\text { Laminação }\end{array}$} & \multirow{4}{*}{$\begin{array}{c}15 \\
\text { anos }\end{array}$} & \multirow{4}{*}{$31.752,00$} & \multirow{4}{*}{$1.587,60$} & Básica Incêndio + Raio & 356,33 & 160,35 & 195,98 \\
\hline & & & & & & Fenômenos Meteorológicos & 239,98 & 107,99 & 131,99 \\
\hline & & & & & & Ventos Fortes & 105,84 & 47,63 & 58,21 \\
\hline & & & & & & Queda de Aeronave & 35,28 & 15,88 & 19,4 \\
\hline \multirow{4}{*}{ Pinus elliotti } & \multirow{4}{*}{$\begin{array}{c}\text { São José do } \\
\text { Norte/RS }\end{array}$} & \multirow{4}{*}{ Resinagem } & \multirow{4}{*}{$\begin{array}{c}15 \\
\text { anos }\end{array}$} & \multirow{4}{*}{$20.886,73$} & \multirow{4}{*}{$1.044,34$} & Básica Incêndio + Raio & 243,68 & 109,66 & 134,02 \\
\hline & & & & & & Fenômenos Meteorológicos & 160,13 & 72,06 & 88,07 \\
\hline & & & & & & Ventos Fortes & 69,62 & 31,33 & 38,29 \\
\hline & & & & & & Queda de Aeronave & 23,21 & 10,44 & 12,77 \\
\hline \multirow{4}{*}{ Pinus elliotti } & \multirow{4}{*}{$\begin{array}{c}\text { São José do } \\
\text { Norte/RS }\end{array}$} & & & & & Básica Incêndio + Raio & 141,63 & 63,73 & 77,9 \\
\hline & & & 15 & 1213043 & 60607 & Fenômenos Meteorológicos & 93,07 & 41,88 & 51,19 \\
\hline & & Laminação & anos & $12.139,43$ & 606,97 & Ventos Fortes & 40,46 & 18,21 & 22,25 \\
\hline & & & & & & Queda de Aeronave & 13,49 & 6,07 & 7,42 \\
\hline & & & & & & Básica Incêndio + Raio & 204,27 & 91,92 & 112,35 \\
\hline Pinus snn & Jaøuariáva/PR & Serraria/ & 15 & 1626066 & 81338 & Fenômenos Meteorológicos & 139,2 & 62,64 & 76,56 \\
\hline Pinus spp. & Jaguariaiva/PR & Laminação & anos & $16.269,66$ & 813,38 & Ventos Fortes & 54,23 & 24,4 & 29,83 \\
\hline & & & & & & Queda de Aeronave & 18,08 & 8,14 & 9,94 \\
\hline & & & & & & Básica Incêndio + Raio & 220,54 & 99,24 & 121,3 \\
\hline Araucária & Quedas do & Serraria/ & 15 & 1626966 & 44109 & Fenômenos Meteorológicos & 148,23 & 66,7 & 81,53 \\
\hline Araucarıa & Iguaçu/PR & Laminação & anos & $16.269,66$ & 441,09 & Ventos Fortes & 54,23 & 24,4 & 29,83 \\
\hline & & & & & & Queda de Aeronave & 18,08 & 8,14 & 9,94 \\
\hline & & & & & & Básica Incêndio + Raio & 237 & 106,65 & 130,35 \\
\hline Seringueira & Votuporanga/ & Produção de & 15 & 1748377 & 474 & Fenômenos Meteorológicos & 159,3 & 71,69 & 87,62 \\
\hline Seringueira & & látex & anos & $17.483,11$ & $4 / 4$ & Ventos Fortes & 58,28 & 26,23 & 32,05 \\
\hline & & & & & & Queda de Aeronave & 19,43 & 8,74 & 10,69 \\
\hline & & & & & & Básica Incêndio + Raio & 894,59 & 402,56 & 492,02 \\
\hline Teca & Taganrá da & Serraria/La & 15 & 6500403 & 32070 & Fenômenos Meteorológicos & 601,28 & 270,58 & 330,7 \\
\hline leca & Serra/MT & minação & anos & $05.994,03$ & $3.229,10$ & Ventos Fortes & 219,98 & 98,99 & 120,99 \\
\hline & & & & & & Queda de Aeronave & 73,33 & 33 & 40,33 \\
\hline & & & & & & Básica Incêndio + Raio & 894,59 & 402,56 & 492,02 \\
\hline Cedro & Campo & Serraria / & 15 & & & Fenômenos Meteorológicos & 601,28 & 270,58 & 330,7 \\
\hline Australiano & Belo/MG & Laminação & anos & $65.994,03$ & $3.229,70$ & Ventos Fortes & 219,98 & 98,99 & 120,99 \\
\hline & & & & & & Queda de Aeronave & 73,33 & 33 & 40,33 \\
\hline & & & & & & Básica Incêndio + Raio & 894,59 & 402,56 & 492,02 \\
\hline $\begin{array}{l}\text { Mogno } \\
\text { Africano }\end{array}$ & Curvelo/MG & $\begin{array}{l}\text { Serrarıa / } \\
\text { Jaminacão }\end{array}$ & 15 & $65.994,03$ & $3.229,70$ & Fenômenos Meteorológicos & 601,28 & 270,58 & 330,7 \\
\hline & & & & & & Ventos Fortes & 219,98 & 98,99 & 120,99 \\
\hline & & & & & & Básica Incêndio + Raio & 306,71 & 138,02 & 75,42 \\
\hline Parić́ & Dom & Corte Pase & & $\mathrm{R} \$$ & 113130 & Fenômenos Meteorológicos & 206,15 & 92,77 & 113,38 \\
\hline Parıcá & Eliseu/PA & Corte Raso & anos & $22.626,00$ & 1.131 .30 & Ventos Fortes & 75,42 & 33,94 & 41,48 \\
\hline & & & & & & Queda de Aeronave & 25,14 & 11,31 & 13,83 \\
\hline & & & & & & Básica Incêndio + Raio & 452,96 & 203,83 & 249,13 \\
\hline Acócia & Minas do & & 15 & $\mathrm{R} \$$ & 167076 & Fenômenos Meteorológicos & 304,45 & 137 & 167,45 \\
\hline Acacia & Leão/RS & Múltiplo & anos & $33.425,20$ & $1.6 / 0, / 6$ & Ventos Fortes & 111,38 & 50,12 & 61,26 \\
\hline & & & & & & Queda de Aeronave & 37,13 & 16,71 & 20,42 \\
\hline
\end{tabular}

Fonte: Dados da pesquisa.

A inclinação da área plantada também exerce uma função importante na operação de supressão e combate ao fogo (JAISWAL et al., 2002), já que o fogo se espalha com maior facilidade em áreas mais inclinadas e nelas o controle é mais difícil de ser realizado.

Determinado o risco da área, os fatores que podem influenciar no valor do prêmio do seguro de florestas são: a espécie a ser segurada, o seu ciclo, idade, a finalidade de uso da madeira e o tipo de cobertura desejada na contratação da apólice do seguro. A apólice é o instrumento do contrato que regula as convenções ajustadas entre o segurado e a seguradora. Ela deve consignar todos os riscos assumidos pela seguradora, o valor do objeto segurado, o prêmio devido ou pago pelo segurado e todas as demais estipulações que forem objeto do contrato e nela ajustadas (MAPFRE, 2016).

Determinado o risco da área, os fatores que podem influenciar no valor do prêmio do seguro de florestas são: a espécie a ser segurada, o seu ciclo, idade, a finalidade de uso 
da madeira e o tipo de cobertura desejada na contratação da apólice do seguro. A apólice é o instrumento do contrato que regula as convenções ajustadas entre o segurado e a seguradora. Ela deve consignar todos os riscos assumidos pela seguradora, o valor do objeto segurado, o prêmio devido ou pago pelo segurado e todas as demais estipulações que forem objeto do contrato e nela ajustadas (MAPFRE, 2016).

Percebe-se que os maiores valores de área em risco, POS e prêmio do seguro são para as espécies: teca, cedro australiano e mogno africano, possivelmente pelo fato de serem as espécies com maior valor agregado, ou seja, que possuem maiores preços de venda no mercado devido as suas características específicas e também por terem um ciclo de corte mais longo. O menor valor para essas mesmas variáveis foi encontrado para o eucalipto para celulose/energia, que das opções apresentadas é o de menor valor agregado e de menor ciclo de corte. Em contrapartida o eucalipto para serraria/laminação com ciclo de 15 anos foi o segundo maior valor para essas variáveis.

A cobertura básica é aquela na qual a seguradora indeniza os danos materiais causados aos bens segurados em consequência de incêndio e queda causada por raio, até o LMI contratado por esse tipo de cobertura (MAPFRE, 2016). Os fenômenos meteorológicos, ventos fortes e queda por aeronaves são as coberturas adicionais disponíveis no questionário de cotação trabalhado. Percebe-se que em todos os plantios, os maiores valores do seguro são os de cobertura básica, seguidos pelos fenômenos meteorológicos, ventos fortes e queda de aeronave, em ordem decrescente de valores.

\section{CONCLUSÕES}

O Programa de Subvenção do Seguro Rural é um programa que fornece auxílio financeiro permitindo a redução dos custos do seguro rural para o produtor. Ele vem produzindo resultados positivos, já que o crescimento na contratação do seguro rural.

A área coberta por seguro de florestas integradas ao PSR representa um percentual baixo das florestas totais plantadas no país, mas, apesar disso, o mercado deve ser considerado promissor, já que é percebido um aumento significativo da contratação do seguro de florestas desde o ano de implementação do PSR.

Entre as cotações do seguro de florestas realizadas para os plantios florestais, os maiores valores do seguro foram para as espécies cedro, teca e mogno africano, como fins de serraria/laminação; e o menor valor foi para eucalipto, com fins de celulose/energia. Os principais fatores que influenciam no valor do risco da área do seguro de florestas estão relacionados basicamente a três aspectos: manejo, implementação e condução do plantio; localização do plantio; e estrutura da fazenda onde o plantio está localizado. Os maiores valores de prêmio são da cobertura básica, seguidos pelos fenômenos meteorológicos, ventos fortes e queda de aeronave, em ordem decrescente de valores.

\section{REFERÊNCIAS}

BATISTA, A. C. Detecção de Incêndios Florestais por Satélites. Revista Floresta, Curitiba, v. 34, n. 2, p. 237241, 2004.

FILHO, E. P.; SANTOS, P. E. T.; FERREIRA, C. A. Eucaliptos indicados para plantio no estado do Paraná. 2006 [acesso em 19 ago. 2016]. Disponível em: https://www.agencia.cnptia.embrapa.br/Repositorio/doc1 29_000hlqx4sov02wx7ha0rww4wo51xqt32.pdf

IEL/CNA/SEBRAE. Instituto Euvaldo Lodi-Iel; Confederação Nacional Da Agricultura-Cna; Serviço Brasileiro De Apoio Às Micro E Pequenas EmpresasSebrae. Estudo sobre a eficiência econômica e competitividade da cadeia agroindustrial da pecuária de corte no Brasil. Brasília. 403p. 2000.

INDÚSTRIA BRASILEIRA DE ÁRVORES [homepage na internet]. Relatório IBÁ. 2015 [acesso em 16 jun. 2016]. Disponível em: http://iba.org/images/shared/iba_2015.pdf

JAISWAL, R. K.; MUKHERJEE, S.; RAJU, K. D.; SAXENA, R. Forest fire risk zone mapping from satellite imagery and GIS. Intenational Journal of Applied Earth Observation and Geoinformation, v. 4, n. 1, p. 1-10, 2002.

MAPA - Ministério da Agricultura, Pecuária e Abastecimento [homepage na internet]. Atlas do Seguro Rural. 2016a [acesso em 25 maio 2016]. Disponível em: http://indicadores.agricultura.gov.br/atlasdoseguro/index. htm

MAPA - Ministério da Agricultura, Pecuária e Abastecimento. Carta de serviços ao cidadão. 2016b [acesso em 2 jun. 2016]. Disponível em: http://www.agricultura.gov.br/portal/page/portal/InternetMAPA/pagina-inicial/carta-de-servico-aocidadao/politica-agricola/seguro-rural

MAPFRE Seguros. Seguro de Florestas: Condições Gerais. [acesso em 29 ago. 2016]. Disponível em: https://www.mapfre.com.br/seguro-br/images/cg15414900441-2013-41-v10-vigencia-01-07-2014-a-1908-2014_tcm909-146549.pdf

REZENDE, J. L. P.; OLIVEIRA, A. D. Análise Econômica e Social de Projetos Florestais. 3 ed. Viçosa: UFV, 2013, 385p.

SUSEP - Superintendência de Seguros Privados. [homepage na internet]. [acesso em 25 maio 2016]. Disponível em: http://www.susep.gov.br/menu/informacoes-aopublico/planos-e-produtos/seguros/seguro-rural

SILVA, F. L.; GRIFFITH, J. J.; JACOVINE, L. A. G.; VLADARES, J. H.; FERNANDES, M. A. S.; SILVA, E. C. G. Estudo da relação de confiança em programa de fomento florestal de indústria de celulose na visão dos produtores rurais. Revista Árvore, Viçosa, v. 33, n. 4, p. 723-732, 2009. 